\author{
Илияна Генев-Пухалева \\ Uniwersytet Warszawski \\ i.genew-puhalewa@uw.edu.pl
}

\title{
НАЗОВАВАНЕТО НА НАЙ-НОВИТЕ РЕАЛНОСТИ И ВИРТУАЛНОСТИ (ПО ПРИМЕРИ ОТ КИБЕРЕКОЛОГИЯТА)
}

В настоящата статия на фокус са названията на понятия, ориентирани към днешното и бъдещото развитие на технологиите, компютърните системи и свързаните с тях възприятия и преживявания. Разглеждат се структурните и семантичните особености на избрани номинации, както и начините за въвеждането им в специализираните текстове. Предметната област, която бе избрана за наблюдение, е тази на киберекологията. Под киберекология се разбира:

описанието и обсъждането на различни феномени, формирали се под влияние на съвременното динамично развитие на комуникационните технологии, електронните медии и интерактивните форми и практики на общуване, познание и споделяне на съдържание в условията на глобалните електронни/компютърни мрежи, чатове, форуми, корпоративни сайтове, блогове. (онлайн: http://cyberecology-bg.com/, достъп на 10.12.2017²).

Отговорьт на въпроса „кой се занимава с киберекология“ е: „съвременните философи“" и това е очаквано, като се има предвид, че отвечен проблем на философията е „какво е реалност“ (от един или друг вид). Следователно може да се твърди, че специализираният език на киберекологията е всъщност подезик на съвременната философия и по-точно на философията, която е ориентирана към бъдещето.

Като примерен казус на проучването може да послужи системната група на единиците, съдържащи елемента кибер-, и на първо място самото название на разискваната предметна област. Опорният терминоелемент екология участва в киберекология (или екология на виртуалните реалности) с по-ши-

\footnotetext{
${ }^{1}$ Форум на киберекологията в България е едноименното електронно списание Киберекология, с главен редактор проф. д-р Силвия Минева, чието издаване е част от научноизследователски проект, вж. http://cyberecology-bg.com.
} 
роко съдържание в сравнение с изначално формираното в контекста на природните науки и то е следното: „познанието за различни видове среда според тяхната обитаемост и според начина на пребиваване, действие и взаимодействие на обитателите им“ [Минева 2015: 6]. Налице е ново приложение на екологичната парадигма - в случая тя служи за осмислянето на компютърнобазираните виртуални среди, чието „обиталище“ е преди всичко интернет, интерпретиран като вид „екосистема“. Явно е, че иновативното използване на дадения изследователски модел има отражение и върху семантичното развитие на екология като термин и терминолемент.

Тук е мястото да подчертая, че названията, които са обект на изследователския ми интерес, представляват лексикални иновации (еднословни и фразеологични, структурни и семантични). Най-новата лексика в българския език е задълбочено проучена в редица трудове, в които подробно се описват основните типове новообразувания, както и най-характерните тенденции при тях ${ }^{2}$. Науката за неологизмите не оставя без внимание новите технологии - разглежда ги като „концептосфера“, представена от множество концепти за „иновационни фрагменти от действителността, за действия и свойства, свързани с тях“ [Благоева, Колковска 2013: 349]. Към тази концептосфера безспорно се отнасят и новообразуванията с компонент кибер-, който се анализира в контекста на неологичната деривация и се определя като „интернационален радиксоид“, подобно на авио- авто-, био- видео-, енерго-, фото-, mеле- и др. [пак там, с. 302]. Изтъква се също, че като формантен компонент ${ }^{3}$ има повишена активност и участва в словообразувателни модели, по които се произвеждат цели серии нови сложни имена. Голяма част от тях са хибриди, чиято втора основа е домашна дума, напр.: киберпространство, кибервойна, кибер-знание, киберармия, кибероръжие и др. Регистрират се три нови значения на кибер-: 1. който се създава, изгражда с помощта на компютьрни технологии: киберизкуство, киберкултура, 2. отнасящ се до компютьрни игри киберигри, киберолимпиада, киберспорт, киберсъстезание, кибершампион, 3. който се отнася до интернет, до виртуалното пространство киберагресия, кибератака, кибербандит, кибербезопасност, киберсекс, киберсигурност, кибертероризъм [пак там, с. 302]. Тълкуването на cyber/cyber- на английска езикова почва е сходно с предложеното от Д. Благоева и С. Колковска, следователно в семантично отношение не се наблюдава някакво специфично българско развитие на този компонент [срв. онлайн: https:/en.oxforddictionaries. com/definition/cyber, достъп на 20.12.2017].

\footnotetext{
${ }^{2}$ Вж. разработката на Д. Благоева и С. Колковска и цитираната там литература в Българска лексикология и фразеология. Том. І. Българска лексикология, изд. на БАН с авторски колектив Л. Крумова-Цветкова, Д. Благоева, С. Колковска, Е. Пернишка, М. Божилова [Благоева, Колковска 2013: 215 и сл.].

${ }^{3}$ Въпреки че се срещат примери за разделно писане (напр. кибер светове), на настоящия етап кибер не се смята за самостоятелна лексема (вж. слятотото писане на примерите в текста). Срв. с други интернационализми: видео наблюдение, фото услуги, смарт карти.
} 
Въпросът за произхода на кибер- не занимава неолозите, но той се повдига в публикациите по киберекология и затова заслужава отделно внимание. Въвеждайки термина киберпънк, авторът на съответната статия подчертава, че елементът от неговото съдържание 'ориентация към бъдещето на технологиите' „личи още от етимологията на думата [...]. Като съчетание „от две английски думи: cyber - отнасящ се до компютърни технологии и виртуална реалност, и punk - означаващо нещо с ниска стойност“ [Тренчев 2017]. Подобно етимологизуване е симптоматично: от една страна то игнорира познатото (пьрвично) значение на cyber-//кибер- 'който се отнася до кибернетика' ${ }^{4}$, а от друга заличава връзката с гръко-латинската традиция при научното номиниране, припознавайки в елемента англицизъм, а не неокласицизъм 5 .

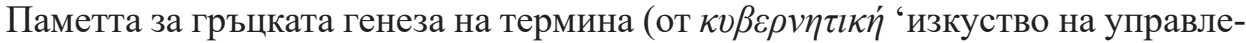
нието' < $\kappa v \beta \varepsilon \rho v-, \kappa v \beta \varepsilon \rho v \eta \dot{\tau}(\eta \varsigma))$ се пази в неговия звуков облик в редица други славянски и неславянски езици - не само в български, но и в руски, сръбски, хърватски, чешки, словашки, немски, унгарски, датски, финландски, чешки и др ${ }^{6}$. Независимо от това неологизмите с кибер- се възприемат като част от лексикалната интернационализация на езиците, в която ролята на език - хегемон днес играе английският, а не класическите езици.

Заемки от английски - материални (вкл. графично неадаптирани) и преводни - са множество други номинации, които са част от киберекологичната лексика, напр.: виртуалност (virtuality), изкуствен (супер-)интелект (artificial intelligence, superintelligence), AüTu (IT - Information Technologies), Big Datal/огромни (обеми от) данни, квантов компютьр (Quantum Coтриter), чат бот (Chatbot), виртуални социални мрежи (virtual social networks), caмообучаваща се дигитална система (Machine Learning) и др.

Както единиците от системната група на кибер-, така и посочените заемки, по своята същност са терминологични (т.е. вече фиксирани като термини) или квазитерминологични (т.е. такива, които са на път да се превърнат в термини - намират се на междинен етап в процеса на терминологизация, като белег за това са опитите за оптимализиране на дефинициите им). Тяхното съдържание се разяснява в нарочна рубрика със заглавие Киберлексикон, която не е справочник с енциклопедични статии, а се състои от обширни тек-

${ }^{4}$ Кибер- е съкращение от кибернетика, което е неокласицизъм, създаден на западноевропейска почва. Известно е, че френският физик Андре-Мари Ампер пръв въвежда в научно обращение термина cybernétique (1834), но популяризирането му се дължи на американския математик Норберт Винер (1948) [https://www.britannica.com/science/cybernetics, 20.02.2018]. С оглед на това cybernetics е регистриран в английския език през 40-те години на XX век, a cyber - през 80-те [ttps://en.oxforddictionaries.com/definition/cybernetics, 12.12.2017]. В киборг и киборгизация участват съкратените основи киб-(ер-)и орг-(анизъм) (< кибернетичен организъм).

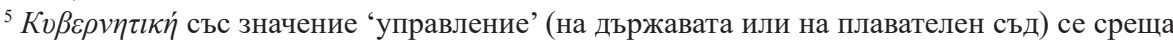

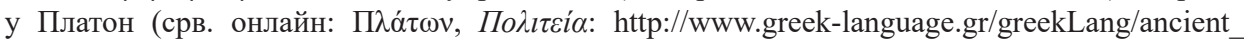
greek/tools/corpora/anthology/content.html? $\mathrm{m}=1 \& \mathrm{t}=529)$.

${ }^{6}$ Срв. с други класицизми от същия корен: губернатор (бълг. и рус.), gouverne и gouvernement (фр.), govern и government (англ.). 
стове с теоретична насоченост (вж. http://cyberecology-bg.com/category /киберлексикон). В тях новите понятия и изразяващите ги термини се фиксират и операционализират, което дава основание тези текстове да се определят като „терминогенериращи“7. Те заслужават вниманието на изследователите не само с това, че са примарни теоретични текстове за българската езикова среда, но и с това, че в тях именно личат особеностите на дадения специализиран език не като вече създаден, а в състояние на зараждане, in statu nascendi.

Специфична черта на специализираните езици и текстове, която ги отличава от общоупотребимия базов език, е не само присъщият им терминологичен лексикон, но и когнитивият синтаксис. Под когнитивен синтаксис се разбират начините за въвеждане на нови терминологични единици (респективно понятия), които по правило са конвенционални и характерни за отделните предметни области. Тези начини (или техники) са обвързани със семантичните отношения между единиците на терминологичния лексикон: част - цяло, род - вид, асоциативни връзки ${ }^{8}$. Може да се каже, че и трите типа отношения са представени в киберекологичния лексикон, като те най-често се комбинират. Това е така, защото в теоретичните терминогенериращи текстове, за разлика от термионофиксиращите, каквито са напр. речниците, справочниците и под. нормативни текстове, се представя цялото понятийно съдържание на термина, а не само неговото терминологично значение .

За илюстрация на въпроса може да послужи въвеждането на неологичния термин соционализъм в статията на Л. Тодорова (тук със съкращения, вж. целия текст онлайн: http://cyberecology-bg.com; подчертаванията са мои - И. Г.-П. $\left.{ }^{10}\right)$ :

Наблюдението и анализът на социалните отношения в сферата на виртуалното общуване показват процес на оформяне и проява на един нов вид индивидуализъм, бихме могли да го определим като „, соиионален” индивидуализъм. Той се характеризира с [...]. Това не е „кооперативен индивидуализъм от Локовски тип", който акцентира върху [...]. Соиионалният индивидуализъм е много различен и от индивидуализма от Хобсов тип, или „еснафския”, характерен за България в т.нар. преходен период (последните двайсетина години). Характеристиката на новия тип индивидуализъм, наблюдаван в хипермодерно развитите общества, се представя от следната обобщена кониептуална рамка: [...]. [Тодорова 2017].

По-долу се представя в схематичен вид въвеждането на соционализъм, като А означава родовото понятие индивидуализъм, $\mathrm{A}_{1}$ и $\mathrm{A}_{2}, \mathrm{~A}_{3}$ - видови понятия (соиионален индивидуализъм, кооперативен индивидуализъм от Локов-

\footnotetext{
7 За типовете специализирани текстове вж. Й. Лукшин и В. Змарзер [Lukszyn, Zmarzer 2001: 45-53].

${ }^{8}$ Вж. Й. Лукшин и В. Змарзер [Lukszyn, Zmarzer 2001: 45-47].

9 За разликата между понятията значение и съдържание на термина вж. М. Попова [Попова 2012: 36-42].

${ }^{10}$ Формата на термина соционализъм се оказва резултат от кондензация на терминологичното словосъчетание соционален индивидуализъм.
} 
ски тип, индивидуализъм от Хобсов тип, еснафски индивидуализъм), a, b, с (и вариантно aa, $b \mathrm{~b}, \mathrm{cc}$ ) - различни характеристики на A:

$\mathrm{A}_{1}$ e A.

$\mathrm{A}_{1}$ се характеризира $\mathrm{c} \mathrm{a}, \mathrm{b}, \mathrm{c}$.

$\mathrm{A}_{1}$ не е $\mathrm{A}_{2}$.

$\mathrm{A}_{1}$ е много различен от (= не е) $\mathrm{A}_{3} u \mathrm{~A}_{4}$.

(Обобщено) $\mathrm{A}_{1}$ e aa, bb, cc.

На равнището на езиковото изразяване когнитивният синтаксис в киберекологичните текстове се разкрива в определени структури, типични за научните текстове като цяло. Зад тях стоят различни логически отношения между понятията: а) тъждество, напр.: А означава В, А е единосъщно на В, A ще се нарича $\mathrm{B}$, под А трябва да се разбира $\mathrm{B}$, от една страна $\mathrm{A}$ е $\mathrm{B}$, от друга $\mathrm{A} e$ С; б) пресичане и/или подчинение: А е подобно на $\mathrm{B}$, А включва в себе си $\mathrm{B}, \mathrm{A}$ съдържа в себе си $\mathrm{B}, \mathrm{A}$ се проявява в $\mathrm{B}, \mathrm{A}$ може да бъде обобщено под термина $\mathrm{B}$, А определя $\mathrm{B}$, А дефинира $\mathrm{B}$; в) противоположност: $\mathrm{A}$ не е $\mathrm{B}$, А не може да бъде $\mathrm{B}$, а е $\mathrm{C}$, А е различно от $\mathrm{B}$ и др.

Част от киберекологичния терминологичен лексикон стават не само названията на понятия, но и названията на основните им характеристики. Например виртуалността се дефинира чрез качества, изразени с прилагателни имена: гладко, прозрачно, плоско, хаптично-оптично. Свидетелство за тяхното терминологизиране е от една страна подробното разясняване на съдържанието им в новия контекст (т.е. дефинирането), а от друга - стремежьт да бъдат изразени чрез номинативна единица от типа на съществителното име. По този начин се превръщат в терминологична лексика и дериватите със суфикс -ост за означаване на абстрактни имена: гладкост, прозрачност, плоскост и паралелно с тях субстантивираните чрез членуване прилагателни: гладкото, прозрачното, плоското. Срв.:

Какъв е портретьт на гладкото? От една страна, то е колкото определение на прозрачното, толкова и негово въпльщение, реализация. [...]

Гладкото и прозрачното дефинират виртуалността веднъж като пространство, и втори път - като специфичен, способен на собствени закони космос, [...].[Пламенов 2017, онлайн: http://cyberecology-bg.com/гладко-и-прозрачно-реалност-ала-вирту/, достъп на 28.02.2018].

Представените дотук наблюдения върху назоваването на нови виртуалности далеч не изчерпват темата, а само маркират въпроси, които предстои да занимават лингвистиката на специализираните езици. За бъдещето на българския език, независимо от средата, в която ще се реализира той (реална и/или виртуална), е важно нещата от това бъдеще да имат български имена. За техния облик отговорност носят както специалистите в съответните области, така и езиковедите. 


\section{Библиография}

Благоева Д., Колковска С. (2013), Динамика и иновационни процеси в българската лексика в края на ХХ и началото на XXI век, [в:] Българска лексикология и фразеология. Том. I. Българска лексикология, Л. Крумова-Цветкова, Д. Благоева, С. Колковска, Е. Пернишка, М. Божилова, Академично издателство „Проф. Марин Дринов“, София, с. 215-378.

Минева С. (2015), Екология на виртуалните реалности: щзо е то, [в:] Екология на виртуалните реалности, сьст. С. Минева и кол., изд. Проектория, София, с. 6.

Пламенов П. (2017), Гладко и прозрачно - реалност ала виртуалност (естетически модификации на виртуалността), http://cyberecology-bg.com/.

Попова М. (2012), Теория на терминологията, Знак '94, Велико Тьрново.

Тодорова Л. (2017), Индивидуализъм, сочионализъм и виртуална комуникачия, http://cyberecologybg.com/

Тренчев С. (2017), Киберпънкът - сбъдващата се научна фантастика, http://cyberecologybg.com/.

Lukszyn J., Zmarzer W. (2001), Teoretyczne podstawy terminologii, Wydział Lingwistyki Stosowanej i Filologii Wschodniosłowiańskich, Uniwersytet Warszawski, Warszawa.

\section{Илияна Генев-Пухалева}

\section{NAMING THE NEW REALITIES AND VIRTUALITIES (USING EXAMPLES FROM THE AREA OF CYBERECOLOGY)}

(Summary)

The paper examines Bulgarian names of concepts (terms or quasi-terms) concerning today's and future developments of technology, computer systems as well perceptions and experiences related to these technologies and systems. The subject area chosen for analysis is that of cyberecology. The author discusses the neological character of the terms naming new realities and virtualities (including the terms with the formal element cyber-), the structural and semantic features of selected terms while emphasizing the influence of English models. The texts studied in the cyberecological area are considered to be term-generating with a view to their primacy within a new language for specific purposes. Furthermore, attention is drawn to the cognitive syntax (i.e. the ways of introducing new concepts) of the cyberecological texts. The general conclusion of the paper is that the linguistic observation of a sublanguage for specific purposes which is in the on-going process of creation is needed considering that it is important for the future of the Bulgarian language to have Bulgarian names for the future realities.

Key words: Bulgarian, language for specific purposes, term creation, cyber, cyberecology 